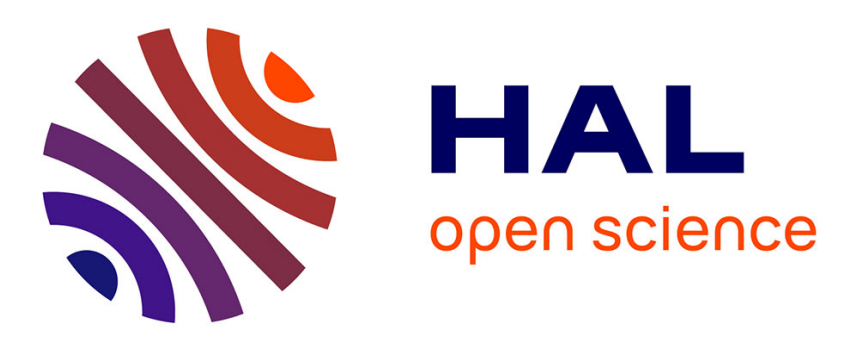

\title{
A MILP Model for Reusable Containers Management in Automotive Plastic Components Supply Chain
}

Eduardo Guzman, Beatriz Andres, Raul Poler

\section{To cite this version:}

Eduardo Guzman, Beatriz Andres, Raul Poler. A MILP Model for Reusable Containers Management in Automotive Plastic Components Supply Chain. 22nd Working Conference on Virtual Enterprises (PRO-VE 2021), Nov 2021, Saint-Etienne, France. pp.179-178, 10.1007/978-3-030-85969-5_15 . emse-03338406

\section{HAL Id: emse-03338406 https://hal-emse.ccsd.cnrs.fr/emse-03338406}

Submitted on 24 Nov 2021

HAL is a multi-disciplinary open access archive for the deposit and dissemination of scientific research documents, whether they are published or not. The documents may come from teaching and research institutions in France or abroad, or from public or private research centers.
L'archive ouverte pluridisciplinaire HAL, est destinée au dépôt et à la diffusion de documents scientifiques de niveau recherche, publiés ou non, émanant des établissements d'enseignement et de recherche français ou étrangers, des laboratoires publics ou privés. 


\title{
A MILP Model for Reusable Containers Management in Automotive Plastic Components Supply Chain
}

\author{
Eduardo Guzman, Beatriz Andres and Raul Poler \\ Research Centre on Production Management and Engineering (CIGIP), Universitat Po- \\ litècnica de València (UPV), Calle Alarcón, 03801 Alcoy, Alicante, Spain
}

\begin{abstract}
The automotive sector operates under the just-in-time (JIT) approach, but variations in demand mean that first-tier suppliers generate an accumulation of stocks at second-tier suppliers. Second-tier suppliers have a limitation of storage space, reason to limit their production to the size of the warehouse, but always attending the first-tier demand plan. A further limitation of the second-tier supplier is the number of empty reusable containers that the first-tier supplier delivers to the second-tier supplier and that are used to package the injected plastic components. The reusable filled containers are returned to the first-tier supplier, according to the plastic components demand plan. Thus, a closed-loop logistic is carried out between first and second-tier suppliers. This study proposes, from the second-tier perspective, a mixed integer linear programming (MILP) model for fleet sizing decisions of the cardboard containers in a production system. The model determines the number of cardboard containers that second-tier supplier has to use when the production is higher than the number of available reusable containers.
\end{abstract}

Keywords: lot-sizing; scheduling; supply chain; mixed integer linear programming; closed-loop supply chain; sustainability.

\section{$1 \quad$ Introduction}

An increasing trend for companies is to work towards meeting environmental and economic requirements and reducing the environmental and social impact of their activities. There is also a rapidly growing interest in reusable packaging, such as wooden pallets and plastic crates and others. Several companies sell products in packaging that can be reused. Returnable transport items (RTI), which represent a specific type of reusable packaging material, including pallets, plastic boxes, or containers (air and maritime), are used today in various industries, for example, in the food sector, in the automotive industry or in the consumer goods industry [1].

The use of reusable packaging is justified by the benefits it can generate, such as the amortization the price of packaging over its useful life [2]. The literature provides several studies showing the environmental benefits associated with reusable containers [3]. Glock and Kim [1] argued that the use of reusable packaging materials rather than single-use packaging materials has the significant contribution of reducing global $\mathrm{CO} 2$ 
emissions from production and transportation, and can significantly minimize the gross energy consumption and the waste generation from transportation.

The difficulty of the reusable container management problem is to have an appropriate supply of empty containers to meet the customer demand. Part of this supply is the result of returns of previously issued containers. A challenging factor is that, during the lead time, the same container may be emitted, returned, re-emitted, etc.

The aim of this research is to investigate the production and fleet-sizing of cardboard containers decisions of a production system when reusable containers are utilized. This model has applicability to the automotive industry, which uses reusable containers to protect and transport plastic parts produced by the second-tier supplier and shipped to the first-tier supplier. The focus of our model is to determine the optimal levels of production and storage rate to minimize the setup times and the quantity of cardboard containers to be purchased when reusable containers, which are property of first-tier supplier, are insufficient to store the parts produced by the second-tier supplier.

The structure of the paper is as follows. Section 2 provides an overview of related work. Section 3 develop a mixed integer linear programming (MILP) model for Reusable Containers Management and contains numerical and negotiation examples. Section 4 concludes the article and offers suggestions for future research.

\section{Literature Review}

This section provides a literature review of relevant contributions in the related research field. The literature focuses on packaging costs and emissions as a target to optimize the use of packaging. Most relevant studies are presented next. Accorsi et al. [4] proposes a mixed-integer linear programming (MILP) model to address the use of reusable packaging in the food industry. The model establishes the number of available packaging and forces to meet the demand for packaging over the planning horizon by encouraging reutilization and recycling. Rajae et al. [2] presents a MILP model that addresses the problem of reusable containers in a reverse supply chain, in a multi-tiered network and under a carbon emmision constraint. Goudenege et al. [5] developed a generic reverse logistics management model focused on investing in and managing reusable packaging at the lowest cost in order to reduce the amount of cardboard used by the company under study. Glock et al. [1] examines a supply chain consisting of a single supplier and several retailers that use returnable transportation items, such as containers or boxes, to facilitate the shipment of products from the supplier to the retailers. The paper presents two mathematical models used to determine the cycle time, container size, individual retailer order quantities, and shipping sequence with the intention of minimizing the average total system costs. Park and Kim [6] present an analytical model for fleet-sizing of containers that are used for the protection (storage of finished parts), transportation and storage of parts between a component plant and multiple assembly plants. Atamer et al. [7] analyses the pricing and production decisions of a manufacturer selling a single product when using reusable containers with stochastic customer demand, and two supply scenarios are analysed: (1) new containers and (2) con- 
tainers returned by customers. In our paper we consider different characteristics addressed in the literature, with the novelty that integrates the decisions of production scheduling and sequencing to determine the optimal use of reusable containers and cardboard containers required to store and send plastic components. The problem modelled adjusts to a real problem that have transmitted to us the first and second-tier supplier of an automotive supply chain.

\section{Problem Definition}

We consider a second-tier supplier that produces plastic components for its assembling in the first-tier supplier. The second-tier supplier produces the parts in moulds that are assembled on injection machines. The machine setup has a high cost associated; therefore, production is constrained by the number of moulds changed in a specific period and the amount of periods that the mould must be mounted within the machine. The main aim is to minimize the costs of production, storage, and machine setups, without incurring in backorders on the first-tier demand plan. Once the second-tier supplier has produced the plastic components, according to its optimal production plan. The parts produced by the second-tier supplier are sent to the first-tier supplier in reusable containers, which are of its property. Reusable containers are limited in capacity and number, when the second-tier supplier produces more parts than he can store in the reusable containers, he has to store in temporary cardboard containers, until empty plastic containers arrive. The use of cardboard containers implies that the second-tier supplier must incur handling costs because they must put the parts in the cardboard containers and then switch to the reusable containers, in addition the manufacturer must purchase the cardboard containers. Fig. 1 shows the closed loop of reusable containers.

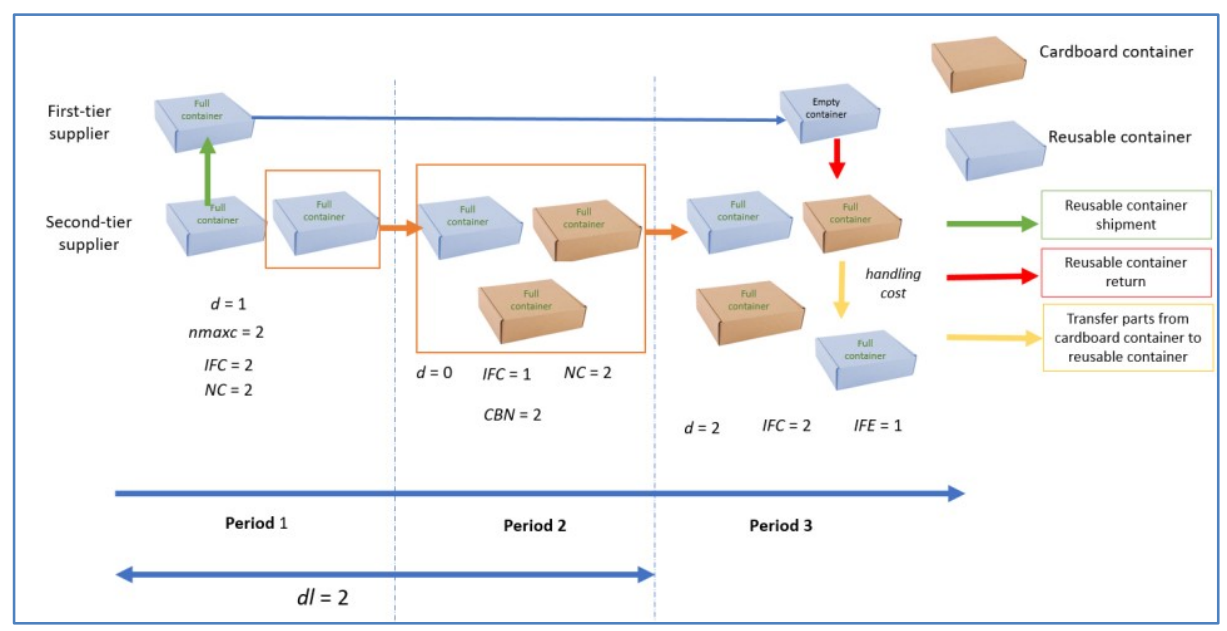

Fig. 1. Closed loop of reusable containers scheme. 
The optimization the second-tier supplier production and scheduling plan, results on grouping production in batches and thus having to stock products. If there are sufficient reusable containers, the produced parts are storage and wait in the warehouse to be delivered to the first-tier supplier, and after a lead time the reusable containers re-circulate and are returned to the second-tier supplier. When there are not sufficient reusable containers, second-tier supplier stores the parts in the cardboard containers.

\subsection{A MILP Model for Reusable Containers Management}

This study proposes, from the second-tier perspective, a Mixed Integer Linear Programming (MILP) model for the production, lot-sizing, and scheduling of automotive plastic components, which takes into consideration the number of reusable containers in circulation throughout the closed-loop logistic. Moreover, the model also determines the number of cardboard containers that second-tier supplier has to use when the production is higher than the number of available reusable containers. This model allows determining the optimal number of reusable containers that should be bought by the firsttier supplier in order not to incur in extra costs due to the use of cardboard containers, which will increase the price of plastic components produced in the second-tier supplier, compromising the supply chain sustainability. This information is useful for both first and second-tier suppliers since with this data both suppliers in the supply chain can negotiate the final price of plastic components, which is contractually dependent on the number of returnable containers delivered by the first-tier supplier to the second-tier supplier.

Table 1. Nomenclature for Reusable Containers Management model

\begin{tabular}{|c|c|}
\hline \multicolumn{2}{|l|}{ Index } \\
\hline$t$ & time period index $t \in\{1, \ldots, T\}$ \\
\hline \multicolumn{2}{|r|}{ (2) } \\
\hline$c h$ & handling cost of cardboard container \\
\hline$c b$ & purchase cost of the cardboard container \\
\hline$c c$ & container capacity \\
\hline$c s$ & setup cost of preparing tool \\
\hline cap & warehouse volume storage capacity \\
\hline$d_{t}$ & demand of containers at period $\mathrm{t}$ \\
\hline $\operatorname{inv0}$ & initial inventory of reusable containers \\
\hline$d l$ & $\begin{array}{l}\text { delay between sending a full reusable container to the first-tier sup- } \\
\text { plier and returning an empty reusable container to the second-tier } \\
\text { supplier }\end{array}$ \\
\hline$i n v p_{0}$ & initial inventory of parts \\
\hline invec $_{0}$ & initial inventory of empty reusable containers \\
\hline invfc $c_{0}$ & initial inventory of filled reusable containers (filed of plastic parts) \\
\hline nmaxc & maximum number of reusable containers \\
\hline$n c_{t}$ & number of mould changes permitted during time period $t$ \\
\hline$x_{t}$ & $\begin{array}{l}\text { number of parts that the machine is able to produce during time } \\
\text { period t }\end{array}$ \\
\hline
\end{tabular}




\begin{tabular}{l|l}
\hline$v$ & volume of containers \\
\hline \multicolumn{2}{l|}{ Decision variables } \\
\hline$C B N_{t}$ & number of cardboard containers \\
\hline$I N V_{t}$ & inventory of parts at the end of time period $\mathrm{t}$ \\
\hline$I E C_{t}$ & inventory of empty reusable containers \\
\hline$I C F_{t}$ & inventory of filled reusable containers \\
\hline$N C_{t}$ & number of containers required \\
\hline$S A_{t}$ & $\begin{array}{l}1 \text { when the mould is set up on machine during period } t, 0 \text { when } \\
\text { mould is set up on machine during period } t-1\end{array}$ \\
\hline$S_{t}$ & $\begin{array}{l}1 \text { when the mould is set up on machine during period } t, \\
0 \text { otherwise }\end{array}$ \\
\hline$X n_{t}$ & number of parts to produce during period t \\
\hline
\end{tabular}

The MILP model formulation for managing the availability of reusable containers in automotive plastic components supply chain is represented below. The objective function minimizes total costs, which comprise setup costs, and investment and handling cost of reusable containers.

$$
\operatorname{Min} z=\sum_{t} c s \cdot S A_{t}+\sum_{t} c h \cdot c b \cdot C B N_{t}
$$

Subject to:

\section{Sequence and setup constraints}

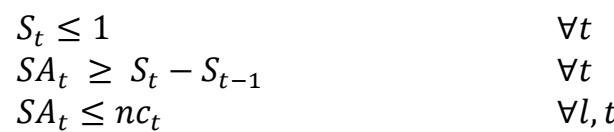

$S A_{t} \leq n c_{t} \quad \forall l, t$

Constraint (2) guarantees that one or neither mould could be set up in production during each period $t$. Constraint (3) guarantee the first tool setup on the machine in period $t$. Constraint (4) guarantees the number of tool changes allowed during period $t$.

\section{Production constraint}

$X n_{t}<=S_{t} \cdot x_{t} \quad \forall t$

Constraint (5) determines the number of parts produced during time period $t$

\section{Inventory constraints}

$$
\begin{array}{ll}
I N V_{t}=\operatorname{invp}_{0}+X n_{t}-d_{t} * c c & \forall t=1 \\
I N V_{t}=I N V_{t-1}+X n_{t}-d_{t} * c c & \forall t>1 \\
N C_{t}=I N V_{t} / c c & \forall t \\
I F C_{t}=\text { invf } c_{0}-d_{t} & \forall t=1 \text { if } N C_{t}>\text { invec }_{0}
\end{array}
$$




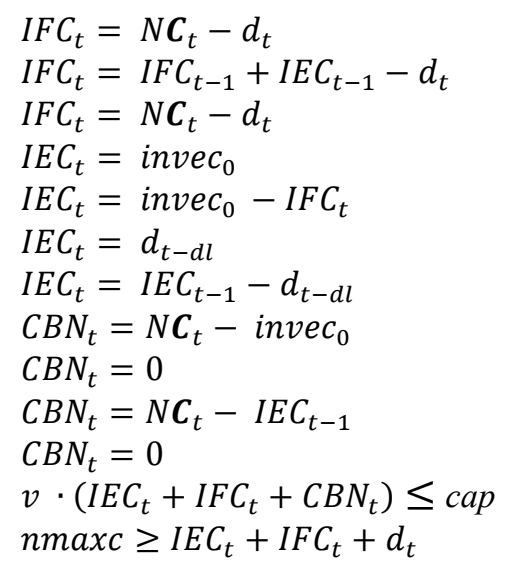

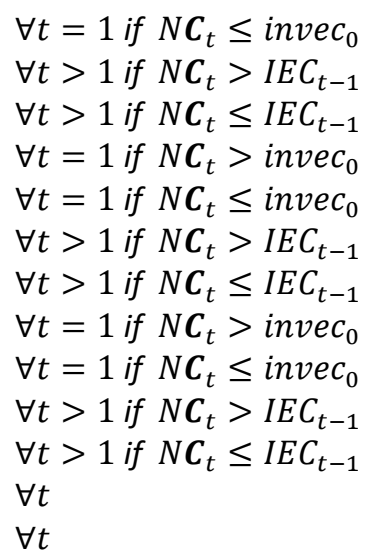

Constraint (6) defines the inventory level of parts that have not been packaged and delivered in a reusable container, i.e., it determines the inventory of overproduction due to the batch sizes. Constraint (7) establishes the required number of reusable and cardboard containers needed for packaging plastic parts. Constraints (8 to 11) manage the inventory of filled reusable containers and control the allocation of plastic parts to reusable and cardboard containers. Constraints (12 to 14) control the inventory of empty reusable containers. Constraints (16 to 19) determine the allocation of parts that have packaged in cardboard containers, due to there are missing empty reusable containers on the second-tier supplier side. It is determined that after a delay time a filled reusable container sent to the first-tier supplier is released as empty reusable container to the second-tier supplier. Constraint (20) is referred to as the storage capacity constraint, which guarantees that the reusable and cardboard container inventory in the warehouse in period $t$ is always less than the capacity of the manufacturer's warehouse. Constraint (21) limits the number of filled and empty reusable containers, since there is a limited number of reusable containers delivered from the first-tier supplier to the second-tier supplier.

\section{Bound and nature variables.}

$\begin{array}{ll}S A_{t}, S_{t} \in\{0,1\} & \forall t \\ I N V_{t}, I C F_{t}, I E F_{t}, C B N_{t}, N C_{t}, X n_{t} \in \mathbb{Z} & \forall t\end{array}$

Constraint (20) denotes the binary character of the variables $S_{t}$ and $S A_{t}$. Constraint (21) specify the integer character of the variables represented.

\subsection{Numerical Experiment}

The model is formulated in Python and solved with Gurobi. The data in this case study has been generated randomly. Table 2 shows the solutions that arrive at one of the generated instances, in this case we have considered 6 periods, in this scenario as can be seen in Table 2 the second level supplier has to use cardboard containers $\left(C B N_{t}\right)$ in 
several periods causing it to incur handling costs. Gurobi takes a few seconds to find the optimum solution on a computer configured with 11 th Gen Intel(R) Core (TM) i71165G7@2.80GHz processors and 16 GB of RAM.

Table 2. Results of MILP model for Reusable Containers Management.

\begin{tabular}{rrrrrrrrr}
\hline $\boldsymbol{t}$ & $\boldsymbol{C B \boldsymbol { N } _ { \boldsymbol { t } }}$ & $\boldsymbol{I E \boldsymbol { C } _ { \boldsymbol { t } }}$ & $\boldsymbol{I F \boldsymbol { C } _ { \boldsymbol { t } }}$ & $\boldsymbol{I N \boldsymbol { V } _ { \boldsymbol { t } }}$ & $\boldsymbol{N} \boldsymbol{C}_{\boldsymbol{t}}$ & $\boldsymbol{S}_{\boldsymbol{t}}$ & $\boldsymbol{S A}_{\boldsymbol{t}}$ & $\boldsymbol{X} \boldsymbol{n}_{\boldsymbol{t}}$ \\
\hline $\mathbf{1}$ & 0 & 1 & 0 & 60 & 15 & 1 & 1 & 32 \\
\hline $\mathbf{2}$ & 9 & 15 & 0 & 40 & 10 & 1 & 0 & 20 \\
\hline $\mathbf{3}$ & 0 & 10 & 2 & 60 & 15 & 1 & 0 & 72 \\
\hline $\mathbf{4}$ & 3 & 13 & 0 & 52 & 13 & 1 & 0 & 44 \\
\hline $\mathbf{5}$ & 4 & 13 & 0 & 68 & 17 & 1 & 0 & 84 \\
\hline $\mathbf{6}$ & 6 & 17 & 0 & 76 & 19 & 1 & 0 & 84 \\
\hline
\end{tabular}

\subsection{Collaboration Scheme}

Figure 2 depicts the process of negotiating the price of plastic components produced by the second-tier supplier. The price of the plastic components is determined by (i) the number of reusable containers that the first-tier supplier delivers to the second-tier supplier; (ii) the number of cardboard containers that the second-tier supplier has to buy (if the number of empty reusable containers is insufficient to store the plastic components produced by the second-tier supplier); (iii) and the costs associated with the plastic components production process, setup costs. 


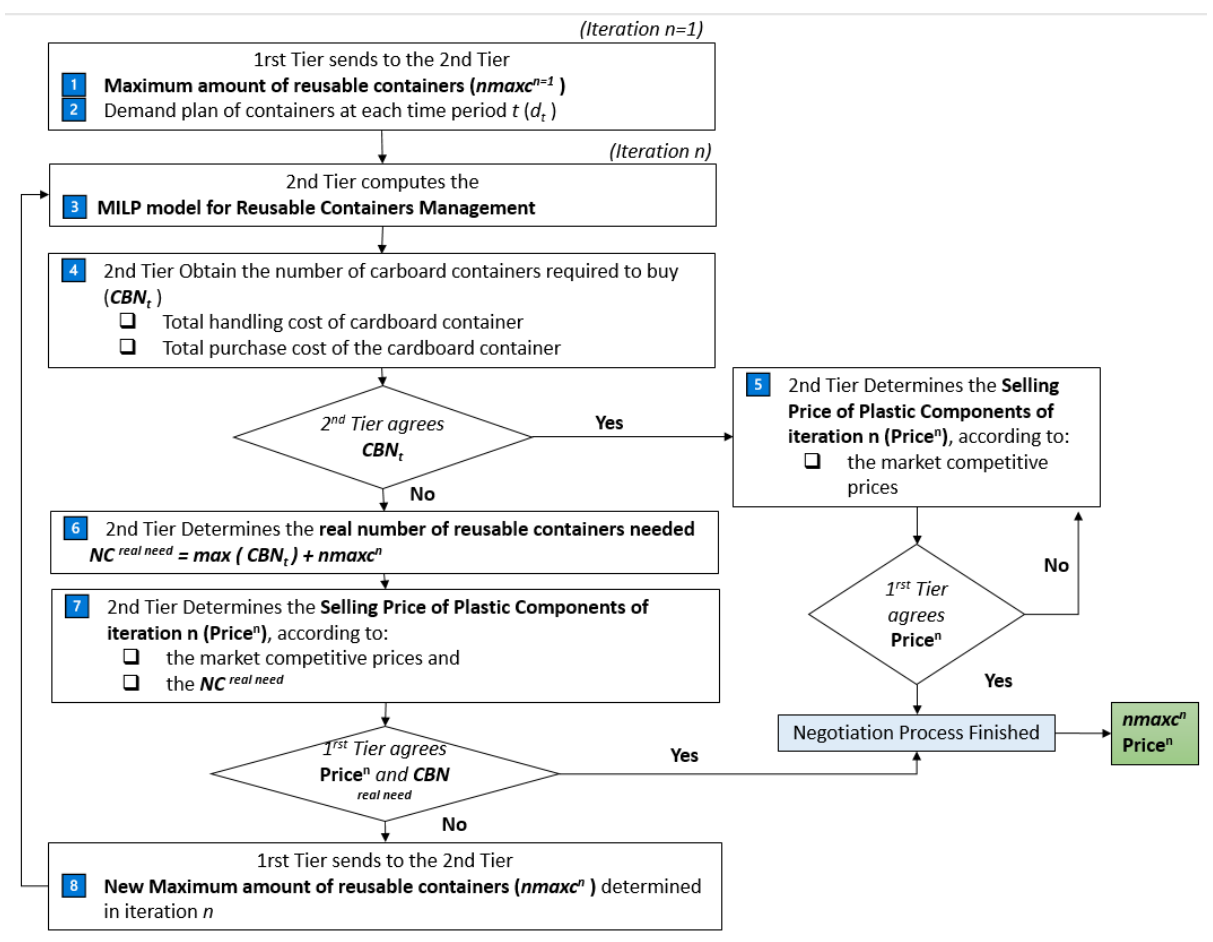

Fig. 2. Flow chart of negotiation process

\section{Conclusions}

In this paper, we provide an integrated approach to help companies consider options when managing their reusable containers. This paper proposes MILP model for optimizing the scheduling of automotive plastic components, which takes into account the use of reusable containers that are used for the protection and transportation of finished products from a second-tier manufacturer to a first-tier supplier. It also determines the number of cardboard containers to be purchased by the second-tier supplier when reusable containers are not available, so the second-tier supplier must incur handling costs to store the parts in cardboard containers until reusable containers are available. Future research lines are led to (i) include in the model the carbon emissions derived from the transport of reusable containers; (ii) the consideration of backorders penalization in the objective function; (iii) and the algorithm implementation of the proposed collaboration scheme, in order to determine the optimal number of reusable containers and the competing price of plastic components.

Acknowledgments. Funding for this work has been provided by the Conselleria de Educación, Investigación, Cultura y Deporte - Generalitat Valenciana for hiring predoctoral research staff with Grant (ACIF/2018/170) and European Social Fund with Grant Operational Program of FSE 2014-2020, the Valencian Community. 


\section{References}

1. C. H. Glock and T. Kim, "Container management in a single-vendor-multiple-buyer supply chain,” Logist. Res., vol. 7, no. 1, 2014, doi: 10.1007/s12159-014-0112-1.

2. E. Rajae, B. Mohamed, and Z. Tarik, "Reverse logistic optimization: Application to the collect and the reuse of reusable containers," ACM Int. Conf. Proceeding Ser., 2018, doi: 10.1145/3230905.3230966.

3. C. H. Glock, "Decision support models for managing returnable transport items in supply chains: A systematic literature review," Int. J. Prod. Econ., vol. 183, pp. 561-569, 2017, doi: 10.1016/j.ijpe.2016.02.015.

4. R. Accorsi, G. Baruffaldi, and R. Manzini, "A closed-loop packaging network design model to foster infinitely reusable and recyclable containers in food industry," Sustain. Prod. Consum., vol. 24, pp. 48-61, 2020, doi: 10.1016/j.spc.2020.06.014.

5. G. Goudenege, C. Chu, and Z. Jemai, "Reusable containers management: From a generic model to an industrial case study," Supply Chain Forum, vol. 14, no. 2, pp. 26-38, 2013, doi: 10.1080/16258312.2013.11517313.

6. S. J. Park and D. S. Kim, "Container fleet-sizing for part transportation and storage in a two-level supply chain,” J. Oper. Res. Soc., vol. 66, no. 9, pp. 1442-1453, 2015, doi: $10.1057 /$ jors.2014.111.

7. B. Atamer, I. S. Bakal, and Z. P. Bayindir, "Optimal pricing and production decisions in utilizing reusable containers," Int. J. Prod. Econ., vol. 143, no. 2, pp. 222-232, 2013, doi: 10.1016/j.ijpe.2011.08.007. 